\title{
DNA Methylation Changes Are Associated With an Incremental Ascent to High Altitude
}

\begin{abstract}
Ainash Childebayeva 1,2,3*, Taylor Harman', Julien Weinstein ${ }^{1}$, Jaclyn M. Goodrich², Dana C. Dolinoy 2,5 , Trevor A. Day ${ }^{6}$, Abigail W. Bigham ${ }^{1,7}$ and Tom D. Brutsaert ${ }^{4}$
\end{abstract}

\begin{abstract}
${ }^{1}$ Department of Anthropology, University of Michigan, Ann Arbor, MI, United States, ${ }^{2}$ Department of Environmental Health Sciences, School of Public Health, University of Michigan, Ann Arbor, MI, United States, ${ }^{3}$ Department of Archaeogenetics, Max Planck Institute for the Science of Human History, Jena, Germany, ${ }^{4}$ Department of Exercise Science, Syracuse University, Syracuse, NY, United States, ${ }^{5}$ Department of Nutritional Sciences, School of Public Health, University of Michigan, Ann Arbor, MI, United States, ${ }^{6}$ Department of Biology, Faculty of Science and Technology, Mount Royal University, Calgary, AB, Canada, ${ }^{7}$ Department of Anthropology, University of California, Los Angeles, CA, United States
\end{abstract}

\section{OPEN ACCESS}

Edited by:

Tatum S. Simonson, University of California, San Diego, United States

Reviewed by: Andrew J. Murray, University of Cambridge, United Kingdom Sajid Ali,

University of Agriculture, Peshawar, Pakistan

*Correspondence:

Ainash Childebayeva childebayeva@shh.mpg.de

Specialty section: This article was submitted to Evolutionary and Population Genetics,

a section of the journal

Frontiers in Genetics

Received: 23 April 2019 Accepted: 03 October 2019 Published: 29 October 2019

Citation:

Childebayeva A, Harman T, Weinstein J, Goodrich JM, Dolinoy DC, Day TA, Bigham AW and Brutsaert TD (2019) DNA Methylation Changes Are Associated With an Incremental Ascent to High Altitude.

Front. Genet. 10:1062. doi: 10.3389/fgene.2019.01062
Genetic and nongenetic factors are involved in the individual ability to physiologically acclimatize to high-altitude hypoxia through processes that include increased heart rate and ventilation. High-altitude acclimatization is thought to have a genetic component, yet it is unclear if other factors, such as epigenetic gene regulation, are involved in acclimatization to high-altitude hypoxia in nonacclimatized individuals. We collected saliva samples from a group of healthy adults of European ancestry $(n=21)$ in Kathmandu (1,400 m; baseline) and three altitudes during a trek to the Everest Base Camp: Namche (3,440 m; day 3), Pheriche (4,240 m; day 7), and Gorak Shep (5,160 m; day 10). We used quantitative bisulfite pyrosequencing to determine changes in DNA methylation, a well-studied epigenetic marker, in LINE-1, EPAS1, EPO, PPARa, and RXRa. We found significantly lower DNA methylation between baseline $(1,400 \mathrm{~m})$ and high altitudes in LINE-1, EPO (at 4,240 m only), and RXRa. We found increased methylation in EPAS1 (at 4,240 m only) and PPARa. We also found positive associations between EPO methylation and systolic blood pressure and $R X R$ R methylation and hemoglobin. Our results show that incremental exposure to hypoxia can affect the epigenome. Changes to the epigenome, in turn, could underlie the process of altitude acclimatization.

Keywords: altitude, epigenetics, DNA methylation, hypoxia, incremental ascent

\section{INTRODUCTION}

More than 140 million people worldwide permanently live at high altitudes, and 40 million more visit altitudes above 2,500 m annually (Ward et al., 2000; Moore, 2001). Atmospheric oxygen partial pressure decreases with increasing altitude, and most individuals experience physiological changes in low-oxygen environments, including increased ventilation, increased red blood cell production, and increased heart rate (HR) (Houston and Riley, 1947). A combination of molecular- to the organismal-level changes occurs during high-altitude acclimatization (Sarkar et al., 2003).

The acute response to hypoxia (seconds to hours) involves changes in homeostatic regulation, whereas chronic acclimatization (hours to years) is characterized by gene expression changes in the carotid body, endothelial cells, and other tissues (Kourembanas et al., 1990; Wiener et al., 1996; 
Huey and Powell, 2000). One of main responders to decreasing levels of oxygen is the hypoxia-inducible factor 1 (HIF) pathway. HIF-1 consists of two subunits, oxygen-regulated HIF-1 $\alpha$, and constitutively expressed HIF-1 $\beta$ (Ivan et al., 2001). In normoxic conditions, HIF-1 $\alpha$ is hydroxylated by HIF prolyl hydroxylase (EGLN) and destined for degradation by ubiquitination via the von Hippel-Lindau ubiquitin ligase (Ohh et al., 2000; Epstein et al., 2001). HIF-1a hydroxylation is decreased in hypoxic conditions allowing it to accumulate and dimerize with HIF-1 $\beta$ forming an active HIF-1 transcription factor in the nucleus (Semenza, 2007). HIF is involved in promoting angiogenesis, regulating erythropoiesis, stimulating glycolysis, and inhibiting fatty acid oxidation (Formenti et al., 2010; Haase, 2013; Huang et al., 2014).

Previous studies have shown that mRNA levels of genes involved in the HIF pathway change upon hypoxic exposure, including HIF1A and ARNT in rats and mice (Wiener et al., 1996), mRNA levels of the platelet-derived growth factor $(P D G F-B)$ in human endothelial cells (Kourembanas et al., 1990), and dopamine D2 receptor $(D 2 R)$ in rat carotid body (Huey and Powell, 2000). Given their ability to change upon exposure to environmental factors, epigenetic mechanisms have been hypothesized to play a role the hypoxic response (Brown and Rupert, 2014). Epigenetics refers to mitotically and, in some cases, meiotically heritable changes to gene expression that do not involve changes to DNA sequence and may be reversible (Wolffe and Guschin, 2000; Feil and Fraga, 2011). The most widely studied and best understood epigenetic modification is DNA methylation, an addition of a methyl group to the nucleotide cytosine in a cytosine-guanine dinucleotide (CpG) (Mohn and Schubeler, 2009; Lam et al., 2012). DNA methylation is most commonly associated with gene repression when located in promoter regions of genes (Klose and Bird, 2006).

Epigenetic modifications are known for their plasticity and ability to change based on the environmental conditions (Bollati and Baccarelli, 2010). Previous studies found associations between DNA methylation and pharmaceuticals, exercise, stress, and other exposures (Dolinoy, 2007; Dolinoy and Jirtle, 2008; Senut et al., 2012; Faulk et al., 2014; Non et al., 2016). Decreased oxygen levels are associated with increased production of reactive oxygen species (ROS) that are genotoxic and can affect DNA methylation and the posttranslational modifications to histone proteins (James et al., 2004; Niu et al., 2015). Moreover, epigenetic changes have been observed in cancer cells that are often hypoxic due to the lower oxygen availability of solid tumors (Shahrzad et al., 2007; Baxter et al., 2014). Here, we focused on DNA methylation and exposure to high-altitude hypoxia.

Epigenetic regulation has been studied in the context of high-altitude adaptation in Andeans and Ethiopians (AlkortaAranburu et al., 2012; Childebayeva et al., 2019). Despite this, epigenetic changes associated with acclimatization to high-altitude hypoxia are not well understood (Julian et al., 2014). To determine if short-term exposure to hypoxia affects the epigenome, we recruited individuals trekking to Everest Base Camp in the Nepal Himalaya. We collected saliva samples and various physiological measurements at four different altitudes:
Kathmandu [1,400m; baseline (BL)], Namche (3,440m; day 3), Pheriche (4,240m; day 7), and Gorak Shep (5,160m; day 10).

We determined the DNA methylation status of the repetitive element LINE-1 and the hypoxia-associated genes EPAS1, EPO, $P P A R a$, and RXRa. We chose LINE-1 as the marker of global methylation as it has been shown to have different methylation profiles at high compared to low altitude in multigenerational Andeans of Quechua ancestry (Childebayeva et al., 2019). We examined methylation at EPAS1 as polymorphisms near this locus are associated with hemoglobin levels in Tibetans (Beall et al., 2010), EPO as it is involves in red blood cell production (Eckardt et al., 1992; Dame et al., 1998; Beall et al., 2010), and PPARa and $R X R a$ as these hypoxia-associated genes are involved in lipid metabolism regulation (Keller et al., 1993; Chinetti et al., 2000) and PPARA is associated with adaptation in high-altitude populations in the Himalaya (Keller et al., 1993; Chinetti et al., 2000; Simonson et al., 2010; Horscroft et al., 2017). RXRa and PPARa form a heterodimer that is necessary for PPARa functioning (Chan and Wells, 2009). The aforementioned HIF pathway genes have been chosen due to previous evidence that methylation levels at these genes are associated hypoxia (Rossler et al., 2004; Lachance et al., 2014; Cortese et al., 2016).

\section{MATERIALS AND METHODS}

\section{Ethics and Participant Recruitment}

This study abided by the Canadian Government Tri-Council policy on research ethics with human participants (TCPS2) and the Declaration of Helsinki, except for registration in a database. Ethical approval was received in advance through Mount Royal University Human Research Ethics Board (protocol 100012 and 101361), the Syracuse University Institutional Review Board (protocol 18-006), and the University of Michigan Institutional Review Board (HUM00141118) and harmonized with the Nepal Health Research Council (protocol 109-2017).

This study took place in May 2018 as part of a research expedition in the Khumbu Valley, Everest region of Nepal. We recruited 21 healthy, nonpregnant, nonlactating, nonsmokers between 19 and 52 years of age from a larger research expedition to Everest Base Camp in the Nepal Himalaya. All participants were recruited in Kathmandu via verbal communication and provided written and informed consent prior to voluntary participation in the study. Even though these participants were recruited as a part of a larger research expedition, the research questions and data collection reported here were planned $a$ priori in advance. Participants either were all altitude naive or had an extended period since the last altitude experience ( $>$ 1year). All participants were of self-reported European descent to control for population effects on epigenetics. Participant characteristics can be found in Table 1.

\section{Ascent Profile and Data Collection}

Over the course of 10 days, a team of researchers and study participants trekked from 2,800 to $5,160 \mathrm{~m}$. The ascent profile 
TABLE 1 | Participant characteristics and DNA methylation.

\begin{tabular}{|c|c|c|c|c|}
\hline & Kathmandu (1,400m) & Namche $(3,400 \mathrm{~m})$ & Pheriche $(4,370 \mathrm{~m})$ & Gorak Shep $(5,160 \mathrm{~m})$ \\
\hline LINE-1 & $64.55(3.05)$ & $62.83(3.41)^{\star \star}$ & $63.40(2.12)^{\star}$ & 63.70 (3.63). \\
\hline EPAS1 & $6.48(1.19)$ & $6.55(1.09)$ & $6.95(1.38)^{*}$ & $6.90(1.35)$ \\
\hline EPO & $72.78(4.88)$ & $71.79(4.14)$ & $69.57(4.13)^{\star}$ & $71.22(3.98)$ \\
\hline PPARa & $13.68(4.16)$ & $14.92(4.51)$ & $15.49(3.79)^{\star \star}$ & $16.12(4.09)^{\star \star \star}$ \\
\hline$R X R a$ & $40.01(11.75)$ & $35.13(12.82)^{\star}$ & $32.44(9.05)^{\star \star \star}$ & $33.57(12.98)^{\star \star}$ \\
\hline Hemoglobin (g/dL) & $132.20(26.67)$ & $146.32(18.13)^{\star \star}$ & $149.42(16.84)^{\star \star}$ & $149.63(26.06)$ ** \\
\hline Body mass index & $22.69(2.52)$ & $22.58(2.46)$ & $22.45(2.36)^{\star \star}$ & $22.25(2.34)^{\star \star \star}$ \\
\hline Systolic blood pressure (mmHg) & $119.62(12.29)$ & $124.62(10.60)$ & $120.62(10.91)$ & $126.67(17.98)^{\star}$ \\
\hline Diastolic blood pressure (mmHg) & $83.00(6.61)$ & $87.95(7.61)^{\star \star}$ & $87.19(8.45)^{\star \star}$ & $86.38(9.01)^{\star}$ \\
\hline Peripheral oxygen saturation & $96.86(1.11)$ & $92.67(3.26)^{\star \star \star}$ & $89.29(2.72)^{\star \star \star}$ & $81.48(4.80)^{\star \star \star}$ \\
\hline$\%$ Female & \multicolumn{4}{|c|}{$45.45(24.65,66.26)$} \\
\hline Age (year) & \multicolumn{4}{|c|}{$24.41(8.20)$} \\
\hline
\end{tabular}

Data are means (SD) of average measurement per individual, 95\% confidence interval (Cl) for proportions in brackets. Age is presented as mean (SD).

Significance symbols denote the difference between Kathmandu baseline and each altitude.

$. p<0.10 .{ }^{*} p<0.05 .{ }^{* *} p<0.01$. ${ }^{* *} p<0.001$.

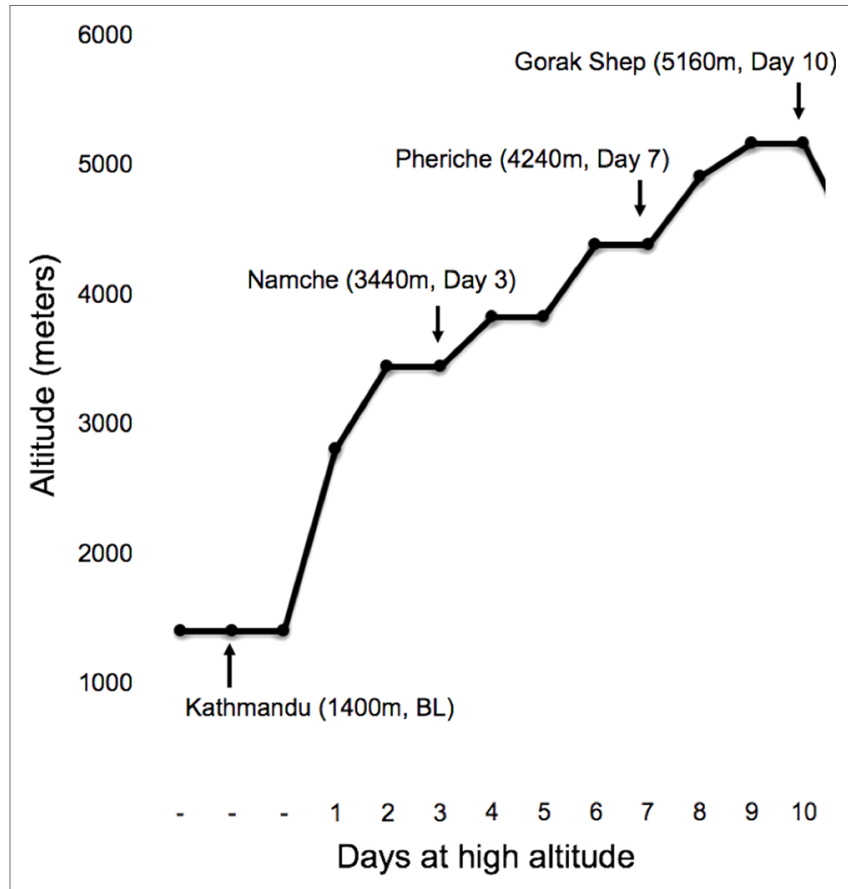

FIGURE 1 | Trekking profile with the sampling locations marked by arrows.

included three nontrekking rest days at 3,440 $\mathrm{m}$ (day 3), 3,820 m (day 5), and 4,240 $\mathrm{m}$ (day 7; Figure 1). In the morning between 6:00 and 8:00 local time at 1,400m (Kathmandu; day 0), 3,440 m (Namche; day 3), 4,240 m (Pheriche; day 7), and 5,160 m (Gorak Shep; day 10), saliva samples for DNA and physiological measures were taken following one night of sleep at each altitude.

With respect to physiological measures, body weight was measured using a portable digital scale (model HBF-516B; Omron, San Ramon, CA, United States). All physiological measures were obtained at rest in a seated position following $>2$-min rest with eyes closed and white noise played through headphones to limit distraction. Blood pressure was assessed using an automated sphygmomanometer. Peripheral oxygen saturation and $\mathrm{HR}\left(\mathrm{min}^{-1}\right)$ were measured using a portable finger pulse oximeter (Masimo SET Rad-5, Danderyd, Sweden). Hemoglobin concentration [(Hb); Hemocue Hemoglobin System, Hb201+, Angelholm, Sweden] was assessed via finger capillary blood sample using sterile lancets and universal precautions. Self-reported acute mountain sickness scores were obtained using the standard Lake Louise Questionnaire (Roach Rc et al., 1993). All phenotypic measures were performed at the same time of day for each participant. Physiological data can be found in Table 1 and Supplementary Table 1.

\section{DNA Methylation}

Saliva samples were collected, and DNA was extracted following a well-established protocol (Quinque et al., 2006). Quantitative pyrosequencing was performed to assess DNA methylation levels of LINE1, EPAS1, EPO, PPARa, and RXRa. Five hundred nanograms of DNA from each sample was bisulfite converted using the EZ-96 DNA Methylation ${ }^{\mathrm{TM}}$ Kit (Zymo Research, Irvine, CA, USA). Bisulfite-converted DNA was amplified using primers for LINE1 and each targeted gene and HotstarTaq plus Master Mix (Qiagen, Valencia, CA, USA). Primer sequences and the locations of the amplicons can be found in Supplementary Table 2. Each sample was pyrosequenced in duplicate using the Pyromark Q96 pyrosequencer (Qiagen). Quality control of the data was assessed using quality control measures built into the pyrosequencing software. All measurements outside of 2 standard deviations from the mean of all samples for each CpG position were excluded. Moreover, measurements with the coefficient of variance between replicates of more than 10 were excluded from further analyses. Duplicate measurements were averaged, as was DNA methylation at $\mathrm{CpG}$ sites within each gene. Statistical modeling was performed on these average DNA methylation values for each subject at each gene. Statistical analyses were performed using the samples collected from the 21 individuals at four altitudes for each LINE1, EPAS1, EPO, and PPARa and 19 for RXRa. No template controls and $0 \%$ 
methylated DNA and 100\% methylated DNA controls (Qiagen) were included in all experiments.

\section{Statistical Analysis}

We used $\mathrm{R}$ version 3.5.1 (R Core Team, 2018). Packages lme4 (Bates et al., 2015), lmerTest (Kuznetsova et al., 2017), ggplot2 (Wickham, 2009), and directlabels (Hocking, 2018) were employed in our statistical analysis and plotting. Linear mixedeffects modeling was used to account for replicate measurements at each altitude. The following linear mixed-effects models were tested. Study participants were modeled as random effects to account for repeated measurements. We included age and sex in the models, since both are known to affect DNA methylation (Liu et al., 2010; Hernandez et al., 2011; Lam et al., 2012; Horvath, 2013).

Yi $(\%$ methylation $) \sim \mathrm{B} 00+\mathrm{B} 01(\mathrm{X})+\mathrm{B} 02($ Sex $)+\mathrm{B} 03($ Age $)+$ (1|ID) + ei, where $X=$ low altitude $(1,440 \mathrm{~m}, \mathrm{BL})$ vs. high altitude $[3,440 \mathrm{~m}$ (day 3 ), vs. $4,240 \mathrm{~m}$ (day 7 ), vs. $5,160 \mathrm{~m}$ (day 10) combined], ID = sample ID.

$\mathrm{Yi}(\%$ methylation $) \sim \mathrm{B} 00+\mathrm{B} 01(\mathrm{X})+\mathrm{B} 02(\mathrm{Sex})+\mathrm{B} 03($ Age $)+$ (1|ID) + ei, where $X=$ altitude $[1,400$ (BL) vs. 3,440m (day 3 ), vs. 4,240m (day 7), vs. 5,160m (day 10)], ID = sample ID.

$\mathrm{Yi}(\%$ methylation $) \sim \mathrm{B} 00+\mathrm{B} 01(\mathrm{X})+\mathrm{B} 02$ (Altitude) + $\mathrm{B} 03($ Sex $)+\mathrm{B} 04($ Age $)+(1 \mid \mathrm{ID})+$ ei, where $X=$ phenotype, altitude $=1,400 \mathrm{~m}(\mathrm{BL}), 3,440 \mathrm{~m}$ (day 3), 4,240m (day 7), 5,160m (day 10), ID = sample ID.

\section{RESULTS}

\section{Hypoxic Exposure Is Associated With Changes in DNA Methylation}

We found LINE1 methylation to be negatively associated with altitude when comparing low altitude $1,400 \mathrm{~m}(\mathrm{BL})$ to high altitude $[3,440 \mathrm{~m}($ day 3$)+4,240 \mathrm{~m}($ day 7$)+5,160 \mathrm{~m}$ (day 10)] ( $\beta=-1.62$ (high), $p=0.005$ ) (Table 2, Figure 2, and Supplementary Figure 1A). Methylation levels of LINE1 were also significantly lower at 3,440 $\mathrm{m}$ (day 3) and 4,240 m (day 7) compared to 1,400 m (BL) (Table 2, Figure 2 and Supplementary Figure 1B).

The association between EPAS1 methylation and high vs. low altitude approached significance ( $\beta=0.36$ (high), $p=0.096$, Supplementary Figure 1B), and only the comparison between $1,400 \mathrm{~m}(\mathrm{BL})$ and 4,240m (day 7) was significant at $p<0.05(\beta=$ $0.58, p=0.033$, Table 2).

EPO methylation was not significantly different between high and low altitude [ $\beta=-1.34$ (high), $p=0.171$ ] (Table 2, Figure 2 and Supplementary Figure 1C), and only the comparison between 1,400 and $4,240 \mathrm{~m}$ (day 7 ) was significant $(\beta=-2.71$, $p=0.023$, Table 2, Figure 2).

$P P A R a$ methylation was positively associated with high altitude $[\beta=1.97$ (high), $p=0.002$, Figure 2 and Supplementary Figure 1D], and the comparisons between $1,400 \mathrm{~m}(\mathrm{BL})$ vs. 4,240 $\mathrm{m}$ (day 7) and 5,160 $\mathrm{m}$ (day 10) were significant (Table 2).

We observed decreased methylation of $R X R a$ associated with high altitude $[\beta=-7.14$ (high), $p<0.001$, Figure 2 and
TABLE 2 | Associations between DNA methylation and altitude.

\begin{tabular}{|c|c|c|c|}
\hline & & $\beta$ & $p$ \\
\hline \multicolumn{4}{|c|}{ LINE-1 } \\
\hline & Low vs. high* & -1.62 (High) & $0.005^{\star \star}$ \\
\hline & $3,440 \mathrm{~m}(\text { day } 3)^{\star \star}$ & -2.04 & $0.003^{* \star}$ \\
\hline & $4,240 \mathrm{~m}(\text { day } 7)^{\star \star}$ & -1.47 & 0.037 * \\
\hline & $5,160 \mathrm{~m}(\text { day } 10)^{\star \star}$ & -1.32 & 0.055 \\
\hline \multicolumn{4}{|c|}{ EPAS1 } \\
\hline & Low vs. high* & 0.36 (High) & 0.096 \\
\hline & $3,440 \mathrm{~m}(\text { day } 3)^{\star \star}$ & 0.27 & 0.310 \\
\hline & $4,240 m(\text { day } 7)^{\star \star}$ & 0.58 & $0.033^{\star}$ \\
\hline & $5,160 \mathrm{~m}(\text { day } 10)^{\star \star}$ & 0.22 & 0.393 \\
\hline \multicolumn{4}{|l|}{$E P O$} \\
\hline & Low vs. high* & -1.34 (High) & 0.171 \\
\hline & $3,440 \mathrm{~m}(\text { day } 3)^{\star \star}$ & -0.61 & 0.603 \\
\hline & $4,240 \mathrm{~m}(\text { day } 7)^{\star \star}$ & -2.71 & 0.023 * \\
\hline & $5,160 \mathrm{~m}(\text { day } 10)^{\star \star}$ & -0.69 & 0.553 \\
\hline \multicolumn{4}{|c|}{ PPARa } \\
\hline & Low vs. high* & 1.97 (High) & $0.002^{* \star}$ \\
\hline & $3,440 \mathrm{~m}(\text { day } 3)^{\star \star}$ & 1.10 & 0.125 \\
\hline & $4,240 \mathrm{~m}(\text { day } 7)^{\star \star}$ & 2.05 & $0.005^{\star \star}$ \\
\hline & $5,160 \mathrm{~m}(\text { day } 10)^{\star \star}$ & 2.76 & $<0.001^{\star \star *}$ \\
\hline \multicolumn{4}{|l|}{$R X R A$} \\
\hline & Low vs. high* & -7.14 (High) & $<0.001^{\text {** }}$ \\
\hline & $3,440 \mathrm{~m}(\text { day } 3)^{\star \star}$ & -5.13 & 0.039 * \\
\hline & 4,240m (day 7) ${ }^{\star \star}$ & -8.70 & $<0.001^{\star \star \star}$ \\
\hline & $5,160 \mathrm{~m}(\text { day } 10)^{\star \star}$ & -7.58 & $0.003^{* *}$ \\
\hline
\end{tabular}

Low vs. high refers to $1,400 m$ (BL) vs. 3,440, 4,240, and 5,160m combined. Otherwise, results indicate the difference between 1,400m (BL) and the altitude listed. All mixed-effects models were adjusted for age and sex. . $p<0.10 .{ }^{*} p<0.05 .{ }^{* *} p<0.01 .{ }^{* * *} p<0.001$.

Supplementary Figure 1E]. Moreover, $R X R a$ methylation levels at 3,440 $\mathrm{m}$ (day 3), 4,240 $\mathrm{m}$ (day 7), and 5,160 $\mathrm{m}$ (day 10) were significantly lower than at 1,400 m (BL) (Table 2).

\section{Associations Between DNA Methylation and Phenotypic Data}

Systolic blood pressure was positively associated with EPO methylation ( $\beta=0.63, p=0.022$, Supplementary Table 3 ). This relationship was seen for baseline, day 3 , and day 10 but not day 7 (Supplementary Figure 2B). We found a significant association between increased $R X R a$ DNA methylation and increased hemoglobin levels $(\beta=0.54, p=$ 0.038 , Supplementary Table 3 ). This general relationship was observed for each altitude, except the low-altitude baseline (Supplementary Figure 2A). We also identified associations approaching significance between PPARa methylation and hemoglobin, $R X R a$ methylation and systolic blood pressure, body mass index, and EPO, and mean arterial pressure and EPO methylation (Supplementary Table 3). We did not find any significant associations between hemoglobin levels and EPAS1 or EPO methylation (data not shown).

\section{DISCUSSION}

Oxygen homeostasis is an essential component of basic physiological homeostasis. In the mitochondria, oxygen is used 


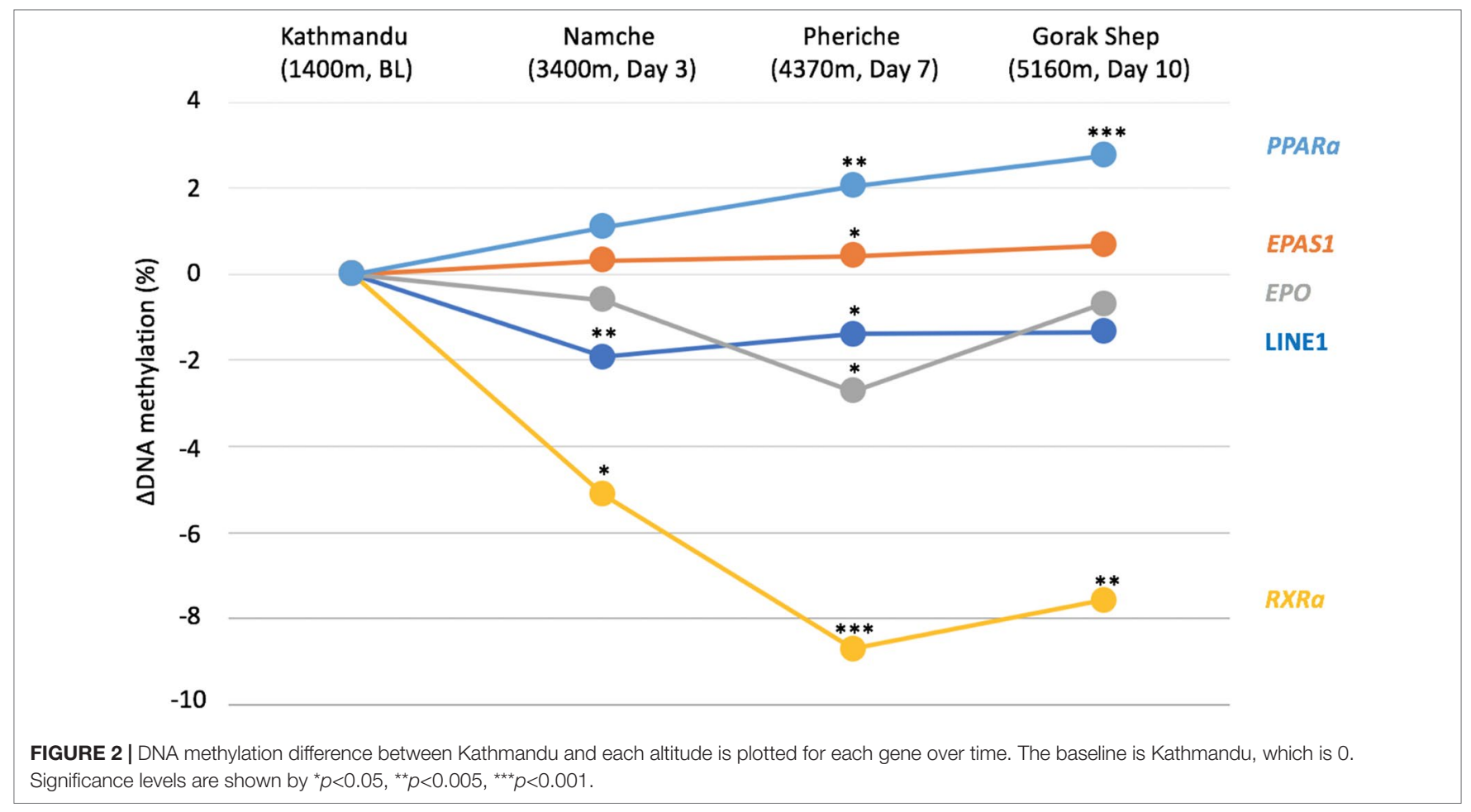

to produce ATP in the process of oxidative phosphorylation (Semenza, 2007). HIF downregulates oxygen consumption by mitochondria and stimulates the glycolytic pathway enzymes (Semenza, 2010). In addition, the HIF pathway is involved in the regulation of fatty acid metabolism (Huang et al., 2014; Liu et al., 2014). Fatty acid oxidation is inhibited in hypoxic conditions as a result of the switch to glycolysis. This leads to accumulation of lipid droplets that have been shown to play a role in protection against ROS (Whitmer et al., 1978; Bensaad et al., 2014). Moreover, the HIF pathway is involved in increasing hemoglobin levels in response to decreased oxygen levels (Franke et al., 2013). In this study, we determined DNA methylation levels of four HIF pathway genes involved in oxygen homeostasis and metabolism, EPAS1, EPO, PPARa, and $R X R a$, and the marker of global methylation, LINE-1, to better understand how the epigenome responds to changes in ambient oxygen availability.

This is the first study to report changes in DNA methylation associated with an incremental ascent to high altitude in a cohort of European ancestry. Previous studies have shown that DNA methylation is affected by chronic exposure to hypoxia (Watson et al., 2010; Yuen et al., 2013; Brown and Rupert, 2014; Childebayeva et al., 2019). However, the effects of short-term hypoxic exposure on the epigenome have not been studied in the context of acclimatization to high altitude in nonacclimatized individuals.

We found decreased LINE-1 methylation, increased PPARa, and decreased $R X R a$ methylation at high compared to low altitude. We also identified increased EPAS1 methylation at
4,240 m (seven days of ascent) and decreased EPO methylation at $4,240 \mathrm{~m}$ compared to $1,400 \mathrm{~m}$. We also found positive associations between $R X R a$ methylation and hemoglobin and between EPO methylation and systolic blood pressure. These findings show that short-term exposure to high-altitude hypoxia can influence the epigenome, which may in turn influence gene expression and phenotype and thus contribute to high-altitude acclimatization.

LINE-1 is a repetitive element, and its methylation level is associated with the global genomic methylation level (Ogino et al., 2008a; Iwagami et al., 2012). The methylation status of LINE-1 has been used as a proxy for the status of the methylome upon exposure to toxicants and in cancer (Chalitchagorn et al., 2004; Kile et al., 2012). Decreased LINE-1 methylation has been shown in cancer and has been associated with genomic instability (Ogino et al., 2008b; Pattamadilok et al., 2008). We found lower LINE-1 methylation levels associated with highaltitude exposure in our cohort. This could be explained by the effect of ROS on the genome, since ROS production is higher in hypoxic conditions (Wongpaiboonwattana et al., 2013; Kloypan et al., 2015). This finding likely reflects the effects of hypoxia as a stressor on the genome.

EPAS1 is involved in activation of oxygen-regulated genes, plays a role in vascular remodeling (Peng et al., 2000), and is an important regulator of EPO, which controls erythropoiesis (Rankin et al., 2007). Importantly, EPAS1 contributes to high-altitude adaptation in Tibetans and shows altered methylation in Andeans (Beall et al., 2010; Childebayeva et al., 2019). We found increased methylation 
of EPAS1 associated with high altitude at 4,240m (day 7), potentially suggesting decreased EPAS1 expression. In comparison, high-altitude adapted Andeans show decreased methylation in hypoxic conditions compared to normoxia (Childebayeva et al., 2019). It is possible that the increase in EPAS1 methylation corresponds to the increase in EPAS1 hydroxymethylation. Hydroxymethylation of a CpG site is an intermediate stage in the demethylation pathway catalyzed by the ten-eleven translocation (TET) family enzymes (Tahiliani et al., 2009). The bisulfite conversion method we used does not differentiate between methylated and hydroxymethylated cytosines (Nestor et al., 2010). It is possible that EPAS1 is in the process of demethylation, which would be expected in hypoxic conditions, although we are seeing a general increase in DNA methylation in our participants.

EPO plays a major role in increased erythropoiesis under HIF control (Koury and Bondurant, 1990; Yoon et al., 2006; Risso et al., 2007). EPO levels rise quickly upon hypoxic exposure (Eckardt et al., 1989). In previous studies of high-altitude acclimatization, EPO has been shown to peak after 1 to 3 days at altitude, followed by a decline in an altitude-dependent manner (Abbrecht and Littell, 1972; Ge et al., 2002). EPO has a conserved HIF-1 binding site (HBS) CGTG in its 3' UTR containing a CpG site (Wang and Semenza, 1993; Wang and Semenza, 1996; Wenger et al., 1998). Decreased methylation status of the HBS has been associated with activation of EPO in hypoxic conditions (Wenger et al., 1998). We found lower methylation upstream of the HBS site at all higher altitudes compared with $1,400 \mathrm{~m}$, and this was statistically significant at $4,240 \mathrm{~m}$. These findings are concordant with previously observed increased EPO expression levels at high altitude (Robach et al., 2004) and suggest that DNA methylation may play a role in this process.

We found a significant positive association between EPO methylation and systolic blood pressure suggesting that lower levels of erythropoietin may be correlated with higher blood pressure, since higher DNA methylation around this locus just upstream of an HBS has been linked to decreased expression of EPO based on previous research (Wenger et al., 1998). Other studies have shown a positive relationship between erythropoietin and human recombinant erythropoietin and blood pressure at rest and exercise in humans and in hypertensive and normotensive rats (Berglund and Ekblom, 1991; Raine and Roger, 1991; Muntzel et al., 1993). More research is necessary to establish if decreased EPO methylation of the locus targeted here is truly associated with higher levels of erythropoietin and if there is a link between EPO methylation and systolic blood pressure, especially since we did not find an association with hemoglobin. Of note, we observed a negative relationship between EPO methylation and systolic blood pressure at 4,240m (day 7), indicating a potential positive link between EPO expression and blood pressure at this altitude. This is the only altitude where we observed a significant change in methylation compared to the baseline. Further investigation is necessary to determine why the positive relationship between EPO expression and systolic blood pressure was identified only at $4,240 \mathrm{~m}$ of altitude (day 7).

PPAR $a$ is a transcription factor involved in controlling fatty acid metabolism and oxidation (Keller et al., 1993). PPARs activate the gene for acyl coenzyme A oxidase, which is the rate-limiting enzyme of the peroxisomal $\beta$-oxidation pathway (Dreyer et al., 1992; Keller et al., 1993). In addition to its role in fatty acid metabolism, PPAR $a$ is also associated with conditions such as obesity and diabetes, as well as various cardiovascular conditions including hypertension and atherosclerosis (Belanger et al., 2002). PPARa promotes fatty acid oxidation and may be involved in the switch from fatty acid oxidation to glucose oxidation via regulation of uncoupling protein 3 (Teruel et al., 2000; Gilde et al., 2003).

HIF transcription factors are known regulators of metabolism (Formenti et al., 2010). Previous studies in cell cultures have shown that PPARa is downregulated by HIF-1 in hypoxic conditions, which may be an adaptive response to hypoxiainduced inflammatory stimuli and metabolic changes (Narravula and Colgan, 2001). Another study of hypoxia exposure during an incremental ascent to the Everest Base Camp has found lower capacity for fatty acid oxidation in skeletal muscle and lower PPARa expression at altitude in the Himalayan Sherpa compared to lowlanders (Horscroft et al., 2017).

We found increased PPARa methylation associated with increasing altitude. The region we targeted is in the promoter region of PPARa suggesting that increased methylation here would be associated with a decrease in expression of PPARa, which is consistent with previous findings of decreased $P P A R a$ expression in hypoxic conditions (Narravula and Colgan, 2001). Decreased expression of PPARa is associated with diminished breakdown of fatty acids (Yoon, 2009). Lower levels of fatty acid oxidation are hypothesized to occur in hypoxic conditions due to the switch to anaerobic glycolysis (Ge et al., 2012).

$R X R a$ is a transcription factor involved in fat metabolism and intracellular receptor signaling. $R X R a$ binds to $P P A R a$ forming an active transcriptional complex able to bind to target genes known as proliferator-responsive elements (Dreyer et al., 1993). Several studies have shown that the activity of the PPARa/RXRa complex is reduced in hypoxic conditions to enable suppression of fatty acid metabolism (Huss et al., 2001; Belanger et al., 2007). The RXRa pathway was altered by hypobaric hypoxia exposure in the rat brain (Sethy et al., 2011). RXRs play a protective role in H9c2 cardiomyocytes from hypoxia/reoxygenation-induced oxidative injury in rats (Shan et al., 2014). We found decreased methylation of the $\mathrm{CpG}$ island located in the promoter region of $R X R a$, which may be associated with increased expression of $R X R a$.

Interestingly, we observed opposite trends in $P P A R a$ and $R X R a$ methylation change. For example, individuals with increased PPARa methylation at high altitude have decreased $R X R a$ methylation (Supplementary Figures 1D, E). Interestingly, individuals with decreased $P P A R a$ methylation (IDs 7 and 17) at high altitude have increased $R X R a$ methylation (IDs 7 and 17), further highlighting the 
interactive nature of $P P A R a / R X R a$. Since we see opposite change in PPARa and $R X R a$ methylation levels, it is unclear whether it indicates increased or decreased activity of the PPARa/RXR $a$ complex.

We found a significant positive association between $R X R a$ methylation and hemoglobin levels. $R X R a$ is a member of the retinoic acid receptor family and is necessary for normal hematopoiesis during development (Melnick and Licht, 1999; Oren et al., 2003). Retinoic acid signaling, specifically retinoic acid receptor $\alpha$, is also involved in adult hematopoiesis (Canete et al., 2017). RXRa has been shown to play a role in hematopoietic signaling in mice (Ricote et al., 2006). However, the role of $\mathrm{RXRa}$ in this process is not well understood in adult humans. Our data suggest that there is a relationship between $R X R a$ and hemoglobin levels. Previous studies have shown that PPARa is associated with hemoglobin levels, which could explain why we see a significant association with $R X R a$ as well, since PPARa and RXRa are known to interact (Simonson et al., 2010; Scheinfeldt et al., 2012).

One of the limitations of our study is the use of saliva as a source of DNA. Saliva comprised white blood cells and epithelial buccal cells. Due to differences in DNA methylation signatures between tissues, any changes in methylation associated with altitude exposure may be confounded by cell type composition differences between altitudes (Lokk et al., 2014). We did not quantify saliva cell types at each altitude and thus were unable to control for this limitation. Furthermore, we only assessed the methylation levels of saliva. Therefore, it is unclear how other tissues responded to hypoxic exposure. However, there are known correlations between saliva and blood. Studies of genome-wide DNA methylation have reported $88.5 \%$ to $96.7 \%$ Pearson correlation between blood and saliva $\mathrm{CpG}$ sites within an individual (Thompson et al., 2013; Smith et al., 2015a). Saliva buccal epithelial cell methylation is also similar to the methylation patters of the brain due to the same ectodermal developmental origin and thus may serve as a proxy for DNA methylation changes in the brain (Smith et al., 2015b). Methylation levels of certain CpG sites are known to be tissue-specific, while methylation levels of other CpG sites correlate between tissue types (Varley et al., 2013). To our knowledge, the genes and loci we chose to study have not been shown to be tissue-specific in terms of methylation levels.

Lastly, we did not collect gene expression data from our participants and thus have not been able to directly link changes in DNA methylation to gene expression.

Overall, we found that short-term exposure to high-altitude hypoxia can affect the epigenome. We observed changes in LINE-1 and hypoxia-pathway associated genes EPAS1, EPO, $P P A R a$, and RXRa. We also found significant associations between DNA methylation of EPO and RXRa and systolic blood pressure and hemoglobin, respectively. Our findings contribute to the growing literature on the role of epigenetics in acclimatization to high altitude. Future studies of the genomewide effects of hypoxia on epigenetics are necessary to better understand the extent of DNA methylation change upon highaltitude exposure.

\section{DATA AVAILABILITY STATEMENT}

The datasets generated for this study are available on request to the corresponding author.

\section{ETHICS STATEMENT}

This study abided by the Canadian Government Tri-Council policy on research ethics with human participants (TCPS2) and the Declaration of Helsinki, except for registration in a data base. Ethical approval was received in advance through Mount Royal University Human Research Ethics Board (Protocol 100012 and 101361), the Syracuse University Institutional Review Board (Protocol 18-006), the University of Michigan Institutional Review Board (HUM00141118) and harmonized with the Nepal Health Research Council (Protocol 109-2017). All participants were recruited via verbal communication and provided written and informed consent prior to voluntary participation in the study.

\section{AUTHOR CONTRIBUTIONS}

$\mathrm{TB}, \mathrm{AC}, \mathrm{AB}, \mathrm{TD}, \mathrm{DD}$, and JG conceived and designed the research. $\mathrm{AC}, \mathrm{TH}$, and JW performed experiments. AC and $\mathrm{TH}$ analyzed data. $\mathrm{TB}, \mathrm{AC}$, and $\mathrm{TH}$ wrote the manuscript with contributions from all authors.

\section{FUNDING}

This work was supported by the University of Michigan (to AC) and the Michigan Lifestage Environmental Exposures and Disease (M-LEEaD) National Institute of Environmental Health Sciences Core Center (P30 ES017885 to DD). AC was supported by the Marshall Weinberg Award and the National Geographic Early Career Award (EC-50834R-18). TD was supported by a Natural Sciences and Engineering Research Council of Canada Discovery grant (RGPIN-2016-04915).

\section{ACKNOWLEDGMENTS}

We would like to acknowledge our study participants from Syracuse University in Syracuse, NY, USA; Mount Royal University in Calgary, AB, Canada; and the MidSweden University in Sweden. This work would have not been possible without our Sherpa guides in Nepal: Nima Sherpa, Tsering Sherpa, Tashi Jangbu, and Fura Tashi Chuserwa, and their porter team. We would like to thank Mackenzie Bronson for her help with sample collection in Gorak Shep and Drs. Mark White and Kerby Shedden for statistical support.

\section{SUPPLEMENTARY MATERIAL}

The Supplementary Material for this article can be found online at: https://www.frontiersin.org/articles/10.3389/fgene.2019.01062/ full\#supplementary-material 


\section{REFERENCES}

Abbrecht, P. H., and Littell, J. K. (1972). Plasma erythropoietin in men and mice during acclimatization to different altitudes. J. Appl. Physiol. 32, 54-58. doi: 10.1152/jappl.1972.32.1.54

Alkorta-Aranburu, G., Beall, C. M., Witonsky, D. B., Gebremedhin, A., Pritchard, J. K., and Di Rienzo, A. (2012). The genetic architecture of adaptations to high altitude in Ethiopia. PLoS Genet. 8, e1003110. doi: 10.1371/journal. pgen. 1003110

Bates, D., Machler, M., Bolker, B. M., and Walker, S. C. (2015). Fitting Linear MixedEffects Models Using lme4. J. Stat. Software 67, 1-48. doi: 10.18637/jss.v067.i01

Baxter, E., Windloch, K., Gannon, F., and Lee, J. S. (2014). Epigenetic regulation in cancer progression. Cell Biosci. 4, 45. doi: 10.1186/2045-3701-4-45

Beall, C. M., Cavalleri, G. L., Deng, L., Elston, R. C., Gao, Y., Knight, J., et al. (2010). Natural selection on EPAS1 (HIF2alpha) associated with low hemoglobin concentration in Tibetan highlanders. Proc. Natl. Acad. Sci. U S A 107, 1145911464. doi: 10.1073/pnas. 1002443107

Belanger, A. J., Lu, H., Date, T., Liu, L. X., Vincent, K. A., Akita, G. Y., et al. (2002). Hypoxia up-regulates expression of peroxisome proliferator-activated receptor gamma angiopoietin-related gene (PGAR) in cardiomyocytes: role of hypoxia inducible factor 1alpha. J. Mol. Cell Cardiol. 34, 765-774. doi: 10.1006/ jmcc.2002.2021

Belanger, A. J., Luo, Z., Vincent, K. A., Akita, G. Y., Cheng, S. H., Gregory, R. J., et al. (2007). Hypoxia-inducible factor 1 mediates hypoxia-induced cardiomyocyte lipid accumulation by reducing the DNA binding activity of peroxisome proliferator-activated receptor alpha/retinoid X receptor. Biochem. Biophys. Res. Commun. 364, 567-572. doi: 10.1016/j.bbrc.2007.10.062

Bensaad, K., Favaro, E., Lewis, C. A., Peck, B., Lord, S., Collins, J. M., et al. (2014). Fatty acid uptake and lipid storage induced by HIF-1alpha contribute to cell growth and survival after hypoxia-reoxygenation. Cell Rep. 9, 349-365. doi: 10.1016/j.celrep.2014.08.056

Berglund, B., and Ekblom, B. (1991). Effect of recombinant human erythropoietin treatment on blood pressure and some haematological parameters in healthy men. J. Intern. Med. 229, 125-130. doi: 10.1111/j.1365-2796.1991.tb00319.x

Bollati, V., and Baccarelli, A. (2010). Environmental epigenetics. Heredity (Edinb) 105, 105-112. doi: 10.1038/hdy.2010.2

Brown, C. J., and Rupert, J. L. (2014). Hypoxia and environmental epigenetics. High Alt. Med. Biol. 15, 323-330. doi: 10.1089/ham.2014.1016

Canete, A., Cano, E., Munoz-Chapuli, R., and Carmona, R. (2017). Role of vitamin a/retinoic acid in regulation of embryonic and adult hematopoiesis. Nutrients 9, 1-18. doi: 10.3390/nu9020159

Chalitchagorn, K., Shuangshoti, S., Hourpai, N., Kongruttanachok, N., Tangkijvanich, P., Thong-Ngam, D., et al. (2004). Distinctive pattern of LINE-1 methylation level in normal tissues and the association with carcinogenesis. Oncogene 23, 8841-8846. doi: 10.1038/sj.onc.1208137

Chan, L. S., and Wells, R. A. (2009). Cross-Talk between PPARs and the Partners of RXR: A Molecular Perspective. PPAR Res. 2009, 925309. doi: 10.1155/2009/925309

Childebayeva, A., Jones, T. R., Goodrich, J. M., Leon-Velarde, F., RiveraChira, M., Kiyamu, M., et al. (2019). LINE-1 and EPAS1 DNA methylation associations with high-altitude exposure. Epigenetics 14, 1-15. doi: 10.1080/15592294.2018.1561117

Chinetti, G., Fruchart, J. C., and Staels, B. (2000). Peroxisome proliferatoractivated receptors (PPARs): nuclear receptors at the crossroads between lipid metabolism and inflammation. Inflamm. Res. 49, 497-505. doi: 10.1007/ s000110050622

Cortese, R., Zhang, C., Bao, R., Andrade, J., Khalyfa, A., Mokhlesi, B., et al. (2016). DNA methylation profiling of blood monocytes in patients with obesity hypoventilation syndrome: effect of positive airway pressure treatment. Chest 150, 91-101. doi: 10.1016/j.chest.2016.02.648

Dame, C., Fahnenstich, H., Freitag, P., Hofmann, D., Abdul-Nour, T., Bartmann, P., et al. (1998). Erythropoietin mRNA expression in human fetal and neonatal tissue. Blood 92, 3218-3225. doi: 10.1182/blood.V92.9.3218

Dolinoy, D. C. (2007). Epigenetic gene regulation: early environmental exposures. Pharmacogenomics 8, 5-10. doi: 10.2217/14622416.8.1.5

Dolinoy, D. C., and Jirtle, R. L. (2008). Environmental epigenomics in human health and disease. Environ. Mol. Mutagen. 49, 4-8. doi: 10.1002/em.20366

Dreyer, C., Keller, H., Mahfoudi, A., Laudet, V., Krey, G., and Wahli, W. (1993). Positive regulation of the peroxisomal beta-oxidation pathway by fatty acids through activation of peroxisome proliferator-activated receptors (PPAR). Biol. Cell. 77, 67-76. doi: 10.1016/S0248-4900(05)80176-5

Dreyer, C., Krey, G., Keller, H., Givel, F., Helftenbein, G., and Wahli, W. (1992). Control of the peroxisomal beta-oxidation pathway by a novel family of nuclear hormone receptors. Cell 68, 879-887. doi: 10.1016/0092-8674(92)90031-7

Eckardt, K. U., Boutellier, U., Kurtz, A., Schopen, M., Koller, E. A., and Bauer, C. (1989). Rate of erythropoietin formation in humans in response to acute hypobaric hypoxia. J. Appl. Physiol. 66 (1985), 1785-1788. doi: 10.1152/ jappl.1989.66.4.1785

Eckardt, K. U., Ratcliffe, P. J., Tan, C. C., Bauer, C., and Kurtz, A. (1992). Agedependent expression of the erythropoietin gene in rat liver and kidneys. J. Clin. Invest. 66 (89), 753-760. doi: 10.1172/JCI115652

Epstein, A. C., Gleadle, J. M., Mcneill, L. A., Hewitson, K. S., O’rourke, J., Mole, D. R., et al. (2001). C. elegans EGL-9 and mammalian homologs define a family of dioxygenases that regulate HIF by prolyl hydroxylation. Cell 107, 43-54. doi: 10.1016/S0092-8674(01)00507-4

Faulk, C., Barks, A., Sanchez, B. N., Zhang, Z., Anderson, O. S., Peterson, K. E., et al. (2014). Perinatal lead ( $\mathrm{Pb})$ exposure results in sex-specific effects on food intake, fat, weight, and insulin response across the murine life-course. PLoS One 9, e104273. doi: 10.1371/journal.pone.0104273

Feil, R., and Fraga, M. F. (2011). Epigenetics and the environment: emerging patterns and implications. Nat. Rev. Genet. 13, 97-109. doi: 10.1038/nrg3142

Formenti, F., Constantin-Teodosiu, D., Emmanuel, Y., Cheeseman, J., Dorrington, K. L., Edwards, L. M., et al. (2010). Regulation of human metabolism by hypoxia-inducible factor. Proc. Natl. Acad. Sci. U S A 107, 12722-12727. doi: 10.1073/pnas.1002339107

Franke, K., Gassmann, M., and Wielockx, B. (2013). Erythrocytosis: the HIF pathway in control. Blood 122, 1122-1128. doi: 10.1182/blood-2013-01-478065

Ge, R. L., Simonson, T. S., Cooksey, R. C., Tanna, U., Qin, G., Huff, C. D., et al. (2012). Metabolic insight into mechanisms of high-altitude adaptation in Tibetans. Mol. Genet Metab. 106, 244-247. doi: 10.1016/j.ymgme.2012.03.003

Ge, R. L., Witkowski, S., Zhang, Y., Alfrey, C., Sivieri, M., Karlsen, T., et al. (2002). Determinants of erythropoietin release in response to short-term hypobaric hypoxia. J. Appl. Physiol. 92 (1985), 2361-2367. doi: 10.1152/ japplphysiol.00684.2001

Gilde, A. J., Van Der Lee, K. A., Willemsen, P. H., Chinetti, G., Van Der Leij, F. R., Van Der Vusse, G. J., et al. (2003). Peroxisome proliferator-activated receptor (PPAR) alpha and PPARbeta/delta, but not PPARgamma, modulate the expression of genes involved in cardiac lipid metabolism. Circ. Res. 92, 518524. doi: 10.1161/01.RES.0000060700.55247.7C

Haase, V. H. (2013). Regulation of erythropoiesis by hypoxia-inducible factors. Blood Rev. 27, 41-53. doi: 10.1016/j.blre.2012.12.003

Hernandez, D. G., Nalls, M. A., Gibbs, J. R., Arepalli, S., Van Der Brug, M., Chong, S., et al. (2011). Distinct DNA methylation changes highly correlated with chronological age in the human brain. Hum. Mol. Genet. 20, 1164-1172. doi: 10.1093/hmg/ddq561

Hocking, T. D. (2018). "Package 'directlabels"'. (R Core Team).

Horscroft, J. A., Kotwica, A. O., Laner, V., West, J. A., Hennis, P. J., Levett, D. Z. H., et al. (2017). Metabolic basis to Sherpa altitude adaptation. Proc. Natl. Acad. Sci. U. S. A. 114, 6382-6387. doi: 10.1073/pnas.1700527114

Horvath, S. (2013). DNA methylation age of human tissues and cell types. Genome Biol. 14, R115. doi: 10.1186/gb-2013-14-10-r115

Houston, C. S., and Riley, R. L. (1947). Respiratory and circulatory changes during acclimatization to high altitude. Am. J. Physiol. 149, 565-588. doi: 10.1152/ ajplegacy.1947.149.3.565

Huang, Li, Li, X., Zhang, L., Sun, L., He, X., Zhong, X., et al. (2014). HIF-1mediated suppression of acyl-CoA dehydrogenases and fatty acid oxidation is critical for cancer progression. Cell Rep. 8, 1930-1942. doi: 10.1016/j. celrep.2014.08.028

Huey, K. A., and Powell, F. L. (2000). Time-dependent changes in dopamine $\mathrm{D}(2)$-receptor mRNA in the arterial chemoreflex pathway with chronic hypoxia. Brain Res. Mol. Brain Res. 75, 264-270. doi: 10.1016/ S0169-328X(99)00321-6

Huss, J. M., Levy, F. H., and Kelly, D. P. (2001). Hypoxia inhibits the peroxisome proliferator-activated receptor alpha/retinoid $\mathrm{X}$ receptor gene regulatory pathway in cardiac myocytes: a mechanism for O2-dependent modulation of mitochondrial fatty acid oxidation. J. Biol. Chem. 276, 27605-27612. doi: 10.1074/jbc.M100277200 
Ivan, M., Kondo, K., Yang, H., Kim, W., Valiando, J., Ohh, M., et al. (2001). HIFalpha targeted for VHL-mediated destruction by proline hydroxylation: implications for O2 sensing. Science 292, 464-468. doi: 10.1126/science.1059817

Iwagami, S., Baba, Y., Watanabe, M., Shigaki, H., Miyake, K., Ida, S., et al. (2012). Pyrosequencing assay to measure LINE-1 methylation level in esophageal squamous cell carcinoma. Ann. Surg Oncol. 19, 2726-2732. doi: 10.1245/ s10434-011-2176-3

James, S. J., Cutler, P., Melnyk, S., Jernigan, S., Janak, L., Gaylor, D. W., et al. (2004). Metabolic biomarkers of increased oxidative stress and impaired methylation capacity in children with autism. Am. J. Clin. Nutr. 80, 1611-1617. doi: 10.1093/ ajcn/80.6.1611

Julian, C., Subudhi, A., Evero, O., Pedersen, B., Dvorkin, D., Lovering, A., et al. (2014). Epigenetic modification of gene expression during human acclimatization to hypobaric hypoxia (885.4). FASEB J. 28, 885.884. doi: 10.1096/fasebj.28.1_supplement.885.4

Keller, H., Dreyer, C., Medin, J., Mahfoudi, A., Ozato, K., and Wahli, W. (1993). Fatty acids and retinoids control lipid metabolism through activation of peroxisome proliferator-activated receptor-retinoid X receptor heterodimers. Proc. Natl. Acad. Sci. U S A 90, 2160-2164. doi: 10.1073/pnas.90.6.2160

Kile, M. L., Baccarelli, A., Hoffman, E., Tarantini, L., Quamruzzaman, Q., Rahman, M., et al. (2012). Prenatal arsenic exposure and DNA methylation in maternal and umbilical cord blood leukocytes. Environ. Health Perspect. 120, 1061-1066. doi: 10.1289/ehp. 1104173

Klose, R. J., and Bird, A. P. (2006). Genomic DNA methylation: the mark and its mediators. Trends Biochem. Sci. 31, 89-97. doi: 10.1016/j.tibs.2005.12.008

Kloypan, C., Srisa-Art, M., Mutirangura, A., and Boonla, C. (2015). LINE-1 hypomethylation induced by reactive oxygen species is mediated via depletion of S-adenosylmethionine. Cell Biochem. Funct. 33, 375-385. doi: 10.1002/ cbf. 3124

Kourembanas, S., Hannan, R. L., and Faller, D. V. (1990). Oxygen tension regulates the expression of the platelet-derived growth factor-B chain gene in human endothelial cells. J. Clin. Invest. 86, 670-674. doi: 10.1172/JCI114759

Koury, M. J., and Bondurant, M. C. (1990). Erythropoietin retards DNA breakdown and prevents programmed death in erythroid progenitor cells. Science 248, 378-381. doi: 10.1126/science.2326648

Kuznetsova, A., Brockhoff, P. B., and Christensen, R. H. B. (2017). ImerTest Package: Tests in Linear Mixed Effects Models. J. Stat. Software 82, 1-26. doi: $10.18637 /$ jss.v082.i13

Lachance, G., Uniacke, J., Audas, T. E., Holterman, C. E., Franovic, A., Payette, J., et al. (2014). DNMT3a epigenetic program regulates the HIF-2alpha oxygensensing pathway and the cellular response to hypoxia. Proc. Natl. Acad. Sci. U S A 111, 7783-7788. doi: 10.1073/pnas.1322909111

Lam, L. L., Emberly, E., Fraser, H. B., Neumann, S. M., Chen, E., Miller, G. E., et al. (2012). Factors underlying variable DNA methylation in a human community cohort. Proc. Natl. Acad. Sci. U S A 109 Suppl 2, 17253-17260. doi: 10.1073/ pnas. 1121249109

Liu, J., Morgan, M., Hutchison, K., and Calhoun, V. D. (2010). A study of the influence of sex on genome wide methylation. PLoS One 5, e10028. doi: 10.1371/journal.pone.0010028

Liu, Y., Ma, Z., Zhao, C., Wang, Y., Wu, G., Xiao, J., et al. (2014). HIF-1alpha and HIF-2alpha are critically involved in hypoxia-induced lipid accumulation in hepatocytes through reducing PGC-1alpha-mediated fatty acid beta-oxidation. Toxicol. Lett. 226, 117-123. doi: 10.1016/j.toxlet.2014.01.033

Lokk, K., Modhukur, V., Rajashekar, B., Martens, K., Magi, R., Kolde, R., et al. (2014). DNA methylome profiling of human tissues identifies global and tissue-specific methylation patterns. Genome Biol. 15, r54. doi: 10.1186/ gb-2014-15-4-r54

Melnick, A., and Licht, J. D. (1999). Deconstructing a disease: RARalpha, its fusion partners, and their roles in the pathogenesis of acute promyelocytic leukemia. Blood 93, 3167-3215. doi: 10.1182/blood.V93.10.3167.410k44_3167_3215

Mohn, F., and Schubeler, D. (2009). Genetics and epigenetics: stability and plasticity during cellular differentiation. Trends Genet. 25, 129-136. doi: 10.1016/j.tig.2008.12.005

Moore, L. G. (2001). Human genetic adaptation to high altitude. High Alt. Med. Biol. 2, 257-279. doi: 10.1089/152702901750265341

Muntzel, M., Hannedouche, T., Lacour, B., and Drueke, T. B. (1993). Erythropoietin increases blood pressure in normotensive and hypertensive rats. Nephron 65 , 601-604. doi: 10.1159/000187571
Narravula, S., and Colgan, S. P. (2001). Hypoxia-inducible factor 1-mediated inhibition of peroxisome proliferator-activated receptor alpha expression during hypoxia. J. Immunol. 166, 7543-7548. doi: 10.4049/ jimmunol.166.12.7543

Nestor, C., Ruzov, A., Meehan, R., and Dunican, D. (2010). Enzymatic approaches and bisulfite sequencing cannot distinguish between 5-methylcytosine and 5-hydroxymethylcytosine in DNA. Biotechniques 48, 317-319. doi: $10.2144 / 000113403$

Niu, Y., Desmarais, T. L., Tong, Z., Yao, Y., and Costa, M. (2015). Oxidative stress alters global histone modification and DNA methylation. Free Radic. Biol. Med. 82, 22-28. doi: 10.1016/j.freeradbiomed.2015.01.028

Non, A. L., Hollister, B. M., Humphreys, K. L., Childebayeva, A., Esteves, K., Zeanah, C. H., et al. (2016). DNA methylation at stress-related genes is associated with exposure to early life institutionalization. Am. J. Phys. Anthropol. 161, 84-93. doi: $10.1002 /$ ajpa.23010

Ogino, S., Kawasaki, T., Nosho, K., Ohnishi, M., Suemoto, Y., Kirkner, G. J., et al. (2008a). LINE-1 hypomethylation is inversely associated with microsatellite instability and $\mathrm{CpG}$ island methylator phenotype in colorectal cancer. Int. J. Cancer 122, 2767-2773. doi: 10.1002/ijc.23470

Ogino, S., Nosho, K., Kirkner, G. J., Kawasaki, T., Chan, A. T., Schernhammer, E. S., et al. (2008b). A cohort study of tumoral LINE-1 hypomethylation and prognosis in colon cancer. J. Natl. Cancer Inst. 100, 1734-1738. doi: 10.1093/ jnci/djn359

Ohh, M., Park, C. W., Ivan, M., Hoffman, M. A., Kim, T. Y., Huang, L. E., et al. (2000). Ubiquitination of hypoxia-inducible factor requires direct binding to the beta-domain of the von Hippel-Lindau protein. Nat. Cell Biol. 2, 423-427. doi: $10.1038 / 35017054$

Oren, T., Sher, J. A., and Evans, T. (2003). Hematopoiesis and retinoids: development and disease. Leuk. Lymphoma 44, 1881-1891. doi: $10.1080 / 1042819031000116661$

Pattamadilok, J., Huapai, N., Rattanatanyong, P., Vasurattana, A., Triratanachat, S., Tresukosol, D., et al. (2008). LINE-1 hypomethylation level as a potential prognostic factor for epithelial ovarian cancer. Int. J. Gynecol. Cancer 18, 711717. doi: 10.1111/j.1525-1438.2007.01117.x

Peng, J., Zhang, L., Drysdale, L., and Fong, G. H. (2000). The transcription factor EPAS-1/hypoxia-inducible factor 2alpha plays an important role in vascular remodeling. Proc. Natl. Acad. Sci. U S A 97, 8386-8391. doi: 10.1073/ pnas. 140087397

Quinque, D., Kittler, R., Kayser, M., Stoneking, M., and Nasidze, I. (2006). Evaluation of saliva as a source of human DNA for population and association studies. Anal. Biochem. 353, 272-277. doi: 10.1016/j.ab.2006.03.021

Raine, A. E., and Roger, S. D. (1991). Effects of erythropoietin on blood pressure. Am. J. Kidney Dis. 18, 76-83.

Rankin, E. B., Biju, M. P., Liu, Q., Unger, T. L., Rha, J., Johnson, R. S., et al. (2007). Hypoxia-inducible factor-2 (HIF-2) regulates hepatic erythropoietin in vivo. J. Clin. Invest. 117, 1068-1077. doi: 10.1172/JCI30117

Ricote, M., Snyder, C. S., Leung, H. Y., Chen, J., Chien, K. R., and Glass, C. K. (2006). Normal hematopoiesis after conditional targeting of RXRalpha in murine hematopoietic stem/progenitor cells. J. Leukoc. Biol. 80, 850-861. doi: 10.1189/jlb.0206097

Risso, A., Turello, M., Biffoni, F., and Antonutto, G. (2007). Red blood cell senescence and neocytolysis in humans after high altitude acclimatization. Blood Cells Mol. Dis. 38, 83-92. doi: 10.1016/j.bcmd.2006.10.161

Roach Rc, Bartsch P., P.H., Hackett, and O., O. (1993). The Lake Louise Acute Moutain Sickness Scoring System. Burlington, VT: Queen City Press.

Robach, P., Fulla, Y., Westerterp, K. R., and Richalet, J. P. (2004). Comparative response of EPO and soluble transferrin receptor at high altitude. Med. Sci. Sports Exerc. 36, 1493-1498. doi: 10.1249/01.MSS.0000139889.56481.E0

Rossler, J., Stolze, I., Frede, S., Freitag, P., Schweigerer, L., Havers, W., et al. (2004). Hypoxia-induced erythropoietin expression in human neuroblastoma requires a methylation free HIF-1 binding site. J. Cell Biochem. 93, 153-161. doi: $10.1002 /$ jcb. 20133

Sarkar, S., Banerjee, P. K., and Selvamurthy, W. (2003). High altitude hypoxia: an intricate interplay of oxygen responsive macroevents and micromolecules. Mol. Cell Biochem. 253, 287-305. doi: 10.1023/A:1026080320034

Scheinfeldt, L. B., Soi, S., Thompson, S., Ranciaro, A., Woldemeskel, D., Beggs, W., et al. (2012). Genetic adaptation to high altitude in the Ethiopian highlands. Genome Biol. 13, R1. doi: 10.1186/gb-2012-13-1-r1 
Semenza, G. L. (2007). Oxygen-dependent regulation of mitochondrial respiration by hypoxia-inducible factor 1. Biochem. J. 405, 1-9. doi: 10.1042/ BJ20070389

Semenza, G. L. (2010). Defining the role of hypoxia-inducible factor 1 in cancer biology and therapeutics. Oncogene 29, 625-634. doi: 10.1038/onc.2009.441

Senut, M. C., Cingolani, P., Sen, A., Kruger, A., Shaik, A., Hirsch, H., et al. (2012). Epigenetics of early-life lead exposure and effects on brain development. Epigenomics 4, 665-674. doi: 10.2217/epi.12.58

Sethy, N. K., Singh, M., Kumar, R., Ilavazhagan, G., and Bhargava, K. (2011). Upregulation of transcription factor NRF2-mediated oxidative stress response pathway in rat brain under short-term chronic hypobaric hypoxia. Funct. Integr. Genomics 11, 119-137. doi: 10.1007/s10142-010-0195-y

Shahrzad, S., Bertrand, K., Minhas, K., and Coomber, B. L. (2007). Induction of DNA hypomethylation by tumor hypoxia. Epigenetics 2, 119-125. doi: 10.4161/ epi.2.2.4613

Shan, P. R., Xu, W. W., Huang, Z. Q., Pu, J., and Huang, W. J. (2014). Protective role of retinoid $\mathrm{X}$ receptor in $\mathrm{H} 9 \mathrm{c} 2$ cardiomyocytes from hypoxia/reoxygenation injury in rats. World J. Emerg. Med. 5, 122-127. doi: 10.5847/wjem.j.i ssn.1920-8642.2014.02.008

Simonson, T. S., Yang, Y., Huff, C. D., Yun, H., Qin, G., Witherspoon, D. J., et al. (2010). Genetic evidence for high-altitude adaptation in Tibet. Science 329, 72-75. doi: 10.1126/science. 1189406

Smith, A. K., Kilaru, V., Klengel, T., Mercer, K. B., Bradley, B., Conneely, K. N., et al. (2015a). DNA extracted from saliva for methylation studies of psychiatric traits: evidence tissue specificity and relatedness to brain. Am. J. Med. Genet. Neuropsychiatr. Genet. 168, 36-44. doi: 10.1002/ajmg.b.32278

Smith, A. K., Kilaru, V., Klengel, T., Mercer, K. B., Bradley, B., Conneely, K. N., et al. (2015b). DNA extracted from saliva for methylation studies of psychiatric traits: evidence tissue specificity and relatedness to brain. Am. J. Med. Genet. B. Neuropsychiatr. Genet. 168B, 36-44. doi: 10.1002/ajmg.b.32278

Tahiliani, M., Koh, K. P., Shen, Y., Pastor, W. A., Bandukwala, H., Brudno, Y., et al. (2009). Conversion of 5-methylcytosine to 5-hydroxymethylcytosine in mammalian DNA by MLL partner TET1. Science 324, 930-935. doi: 10.1126/ science. 1170116

Teruel, T., Smith, S. A., Peterson, J., and Clapham, J. C. (2000). Synergistic activation of UCP-3 expression in cultured fetal rat brown adipocytes by PPARalpha and PPARgamma ligands. Biochem. Biophys. Res. Commun. 273, 560-564. doi: 10.1006/bbrc.2000.2982

Thompson, T. M., Sharfi, D., Lee, M., Yrigollen, C. M., Naumova, O. Y., and Grigorenko, E. L. (2013). Comparison of whole-genome DNA methylation patterns in whole blood, saliva, and lymphoblastoid cell lines. Behav. Genet. 43, 168-176. doi: 10.1007/s10519-012-9579-1

Varley, K. E., Gertz, J., Bowling, K. M., Parker, S. L., Reddy, T. E., Pauli-Behn, F., et al. (2013). Dynamic DNA methylation across diverse human cell lines and tissues. Genome Res. 23, 555-567. doi: 10.1101/gr.147942.112

Wang, G. L., and Semenza, G. L. (1993). General involvement of hypoxia-inducible factor 1 in transcriptional response to hypoxia. Proc. Natl. Acad. Sci. U S A 90, 4304-4308. doi: 10.1073/pnas.90.9.4304
Wang, G. L., and Semenza, G. L. (1996). Molecular basis of hypoxiainduced erythropoietin expression. Curr. Opin. Hematol. 3, 156-162. doi: 10.1097/00062752-199603020-00009

Ward, M., Milledge, J. S., and West, J. B. (2000). High altitude medicine and physiology. London: Arnold.

Watson, J. A., Watson, C. J., Mccann, A., and Baugh, J. (2010). Epigenetics, the epicenter of the hypoxic response. Epigenetics 5, 293-296. doi: 10.4161/epi.5.4.11684

Wenger, R. H., Kvietikova, I., Rolfs, A., Camenisch, G., and Gassmann, M. (1998). Oxygen-regulated erythropoietin gene expression is dependent on a CpG methylation-free hypoxia-inducible factor-1 DNA-binding site. Eur. J. Biochem. 253, 771-777. doi: 10.1046/j.1432-1327.1998.2530771.x

Whitmer, J. T., Idell-Wenger, J. A., Rovetto, M. J., and Neely, J. R. (1978). Control of fatty acid metabolism in ischemic and hypoxic hearts. J. Biol. Chem. 253, 4305-4309.

Wickham, H. (2009). ggplot2: Elegant Graphics for Data Analysis. Elegant Graphics for Data Analysis. New York, NY: Springer. 1-212. doi: 10.1007/978-0-387-98141-3_1

Wiener, C. M., Booth, G., and Semenza, G. L. (1996). In vivo expression of mRNAs encoding hypoxia-inducible factor 1. Biochem. Biophys. Res. Commun. 225, 485-488. doi: 10.1006/bbrc.1996.1199

Wolffe, A. P., and Guschin, D. (2000). Review: chromatin structural features and targets that regulate transcription. J. Struct. Biol. 129, 102-122. doi: 10.1006/ jsbi. 2000.4217

Wongpaiboonwattana, W., Tosukhowong, P., Dissayabutra, T., Mutirangura, A., and Boonla, C. (2013). Oxidative stress induces hypomethylation of LINE-1 and hypermethylation of the RUNX3 promoter in a bladder cancer cell line. Asian Pac. J. Cancer Prev. 14, 3773-3778. doi: 10.7314/ APJCP.2013.14.6.3773

Yoon, D., Pastore, Y. D., Divoky, V., Liu, E., Mlodnicka, A. E., Rainey, K., et al. (2006). Hypoxia-inducible factor-1 deficiency results in dysregulated erythropoiesis signaling and iron homeostasis in mouse development. J. Biol. Chem. 281, 25703-25711. doi: 10.1074/jbc.M602329200

Yoon, M. (2009). The role of PPARalpha in lipid metabolism and obesity: focusing on the effects of estrogen on PPARalpha actions. Pharmacol. Res. 60, 151-159. doi: 10.1016/j.phrs.2009.02.004

Yuen, R. K., Chen, B., Blair, J. D., Robinson, W. P., and Nelson, D. M. (2013). Hypoxia alters the epigenetic profile in cultured human placental trophoblasts. Epigenetics 8, 192-202. doi: 10.4161/epi.23400

Conflict of Interest: The authors declare that the research was conducted in the absence of any commercial or financial relationships that could be construed as a potential conflict of interest.

Copyright (c) 2019 Childebayeva, Harman, Weinstein, Goodrich, Dolinoy, Day, Bigham and Brutsaert. This is an open-access article distributed under the terms of the Creative Commons Attribution License (CC BY). The use, distribution or reproduction in other forums is permitted, provided the original author $(s)$ and the copyright owner(s) are credited and that the original publication in this journal is cited, in accordance with accepted academic practice. No use, distribution or reproduction is permitted which does not comply with these terms. 